\title{
Infliximab treatment for rheumatic disease: clinical and radiological efficacy
}

\section{E W St Clair}

Infliximab is a chimeric anti-tumour necrosis factor $\alpha$ (TNF $\alpha$ ) monoclonal antibody with high affinity and binding specificity for human TNF $\alpha$. Results from several well designed, controlled clinical trials show repeated infusions of infliximab with concomitant methotrexate (MTX) treatment can reduce the signs and symptoms of rheumatoid arthritis (RA). This combination of infliximab and MTX also slows the radiological progression of joint damage, decreases functional disability, and improves qualify of life. These remarkably positive results have led to the investigation of infliximab treatment for other rheumatic diseases. Recently, controlled studies have shown treatment with infliximab can benefit patients with active spondyloarthropathy. TNF $\alpha$ has fast become an important therapeutic target in rheumatology.

. nfliximab, a tumour necrosis factor $\alpha(\mathrm{TNF} \alpha)$ inhibitor, has emerged as a key treatment for rheumatoid arthritis (RA) and other rheumatic diseases. Working at the Kennedy Institute of Rheumatology in London, Ravinder Maini and Marc Feldmann pioneered the early development of infliximab. Since beginning their research together over a decade ago, considerable progress has been made in our understanding of TNF $\alpha$ as an inflammatory mediator and the clinical utility of anticytokines as a therapeutic strategy. Infliximab is now widely used throughout the world for the treatment of RA and a growing list of other inflammatory arthropathies. In this article, I will review the clinical and radiological efficacy of infliximab treatment for RA as well as the recent studies using this agent for the treatment of ankylosing spondylitis and psoriatic arthritis.

Infliximab was derived from a murine antibody against human TNF $\alpha$. However, murine monoclonal antibodies are unattractive as therapeutic agents because of their immunogenicity and unfavourable pharmacokinetics. To decrease immunogenicity and improve the pharmacokinetic profile, the murine antibody was engineered as a chimeric anti-TNF $\alpha$ antibody with a predominance of human amino acid sequences. ${ }^{1}$ The murine antigen binding regions were retained in the chimeric antibody, but the constant regions from the mouse antibody were replaced with the corresponding parts of a human IgGl molecule. The chimeric anti-TNF antibody has been shown to bind soluble and transmembrane TNF $\alpha$ with high specificity and affinity $\left(\mathrm{K}_{\mathrm{a}}=10^{10} / \mathrm{M}\right)$, and forms a stable complex preventing association of $\mathrm{TNF} \alpha$ with its receptor.

\section{RHEUMATOID ARTHRITIS}

Initial studies had shown TNF $\alpha$ as well as other proinflammatory cytokines were abundantly expressed in the synovial tissue of patients with RA. Many investigators were sceptical in the beginning of the anti-TNF $\alpha$ approach, or blocking a lone proinflammatory cytokine. In theory, interleukin 1 and other proinflammatory cytokines could perpetuate the pathological process and compensate for the down regulation of TNF $\alpha$ activity. In 1993, an open label study of infliximab treatment for RA afforded the first inklings TNF $\alpha$ was a viable therapeutic target. ${ }^{2}$ Next, the results of a randomised, placebo controlled trial provided solid evidence for the beneficial effects of infliximab on RA activity. In this trial, 73 patients with active RA were randomly allocated to receive an infusion of placebo or $1 \mathrm{mg} / \mathrm{kg}$ or $10 \mathrm{mg} / \mathrm{kg}$ of infliximab. ${ }^{3}$ Treatment with infliximab produced a rapid and significant reduction in the number of tender and swollen joints and concentrations of serum C reactive protein (CRP). The best responses were obtained with the $10 \mathrm{mg} / \mathrm{kg}$ dose. Not unexpectedly, a single infliximab infusion was inadequate to produce a sustained response. Repeated cycles of treatment were later found to maintain clinical improvement if given frequently enough. ${ }^{4}$ Some patients developed serum antibodies to the foreign antigen binding sequences of infliximab, raising questions about the possible long term efficacy of prolonged treatment.

The clinical efficacy of infliximab treatment for RA was subsequently investigated in a 26 week, double blind placebo controlled, dose ranging study. Eligible patients must have been taking methotrexate (MTX) 7.5-15 mg/wk for at least six months before study entry. The dose of MTX was fixed at 7.5 $\mathrm{mg} / \mathrm{wk}$ for four weeks before randomisation. The 101 patients were randomly assigned in this study to receive placebo or infliximab 1,3, or $10 \mathrm{mg} / \mathrm{kg}$ at weeks $0,2,6$, and 14 , with or without MTX $7.5 \mathrm{mg} /$ week. A control group received placebo infusions and MTX $7.5 \mathrm{mg} /$ week. At a dose of $1 \mathrm{mg} / \mathrm{kg}$, infliximab was more effective with MTX than without MTX treatment, with the former combination producing a higher rate and duration of treatment response. On the other hand, similar response rates were observed for the infliximab 3 and $10 \mathrm{mg} / \mathrm{kg}$ dose groups at week 16, with or without MTX. The Paulus response rates approached $60 \%$ for all of these groups. By week 26 , the responses trended lower for the patients taking infliximab alone compared with those receiving infliximab and MTX.

In this same study, serum antibodies to infliximab were detected in $17.4 \%$ of all infliximab treated patients. ${ }^{5}$ However, higher doses of infliximab and concomitant MTX treatment were associated with lower incidences of serum antibodies to infliximab. In fact, serum antibodies to infliximab were undetectable in the infliximab $10 \mathrm{mg} / \mathrm{kg}$ plus MTX group. Pharmacokinetic analysis showed blood concentrations of infliximab decreased more rapidly in the $1 \mathrm{mg} / \mathrm{kg}$ group than the 3 $\mathrm{mg} / \mathrm{kg}$ and $10 \mathrm{mg} / \mathrm{kg}$ groups. At the lowest dose, the clearance of infliximab may have been speeded by circulating antibodies to infliximab determinants. These studies identified $3 \mathrm{mg} / \mathrm{kg}$ and $10 \mathrm{mg} / \mathrm{kg}$ as potentially the most effective doses and suggested infliximab treatment would be more effective in combination with MTX than alone. Findings from another randomised, placebo controlled trial of infliximab tended to support these conclusions. ${ }^{6}$

Abbreviations: RA, rheumatoid arthritis; MTX, methotrexate; TNF $\alpha$, tumour necrosis factor $\alpha ; C R P, C$ reactive protein 
The clinical and radiological efficacy of repeated infusions of infliximab was further evaluated in the Anti-TNF Trial in RA with Concomitant Therapy (ATTRACT). ${ }^{78}$ To be eligible, patients must have had active RA despite taking at least $12.5 \mathrm{mg} / \mathrm{wk}$ of MTX treatment. The study enrolled 428 eligible patients who were randomly allocated to placebo or $3 \mathrm{mg} / \mathrm{kg}$ or $10 \mathrm{mg} / \mathrm{kg}$ of infliximab every four or eight weeks. All patients received infusions of placebo or infliximab at week 0,2 , and 6 followed by infusions every four or eight weeks. The MTX dose was kept constant during the trial unless it had to be reduced for possible MTX toxicity. The study population had advanced disease, as evidenced by a mean duration of disease ranging from 9-12 years across the five treatment groups. Infliximab treatment was efficacious at all doses compared with placebo. ${ }^{7}$ The ACR20 response rates rose quickly and reached $50 \%-60 \%$ by the 30 week end point. Significantly more patients in the infliximab treatment groups also achieved ACR50 (26\%-31\% v 5\%) or ACR70 (8\%-18\% $v 0 \%)$ responses than those in the MTXplacebo group. The tender and swollen joint counts, pain scores, and serum concentrations of CRP improved by comparable values. The ACR response rates were generally sustained through one year of treatment. ${ }^{8}$ However, at week 54, the ACR50 response rate for the $3 \mathrm{mg} / \mathrm{kg}$ every eight week group was only $21 \%$. While this lowest dose group had a significantly higher ACR50 response rate than the placebo group (8\%), it had notably less clinical efficacy than the other infliximab doses with ACR50 response rates of $34 \%, 38 \%$, and $39 \%$.

In the midst of ATTRACT, a decision was made to extend the trial from 54 to 102 weeks. As a result, some of the patients in the study had a several month gap in their experimental treatment at this midway point. During the second year, the trial was unblinded after analysis of the radiographic data from week 54 had shown infliximab treatment significantly protected against the development of joint damage. Therefore, some of the patients did not complete the study under conditions of blinding.

The radiologicial analysis was performed using rigorous methodology. The amount of joint damage was determined using the van der Heijde modification of the Sharp score. ${ }^{10}$ This method quantifies the extent of bone erosions and joint space narrowing for 44 and 40 joints, respectively. Total scores with this scoring system range from 0-440, with higher scores denoting greater damage. Two experienced readers scored each radiograph and were blinded to the order of the films. At baseline, the total Sharp scores were 67-82 across treatment groups, indicative of moderately severe joint damage.

In the MTX plus placebo control group, the total Sharp score increased from baseline to week 54 by a mean (SD) of 7.0 (10.3). Thus, partial responders to MTX treatment accumulated joint damage over time. All doses of infliximab significantly decreased the radiological progression of joint damage after one year of treatment $(54 \%) .^{8}$ The mean (SD) change in the total Sharp score for the $3 \mathrm{mg} / \mathrm{kg}$ every 8 week, $3 \mathrm{mg} / \mathrm{kg}$ every 4 week, $10 \mathrm{mg} / \mathrm{kg}$ every 8 week, and $10 \mathrm{mg} / \mathrm{kg}$ every 4 week groups, were 1.3 (6.0), 1.6 (8.5), 0.2 (3.6), and -0.7 (3.8), respectively. Significant improvements were noted for the erosion and joint space narrowing components of the total score, implying infliximab treatment slows the progression of both subchondral bone and cartilage injury. In a subgroup analysis, infliximab treatment arms seemed to decrease radiological progression of joint damage for both ACR20 responders and non-responders. Although this finding suggests a TNF $\alpha$ inhibitor such as infliximab can inhibit joint damage independently of its anti-inflammatory effects, at least some of the non-responders by ACR20 criteria have been found to improve in some clinical aspects. Regardless, the results from this trial imply an important role for $\mathrm{TNF} \alpha$ in mediating cartilage and bone destruction. Preliminary analysis of data from the 102 week end point also has shown that infliximab treatment produces significant improvements in functional disability and quality of life. ${ }^{9}$ The potential immu- nogenicity of chronic infliximab treatment remains a subject of investigation, but thus far has not been shown to impact clinical efficacy in a significant way.

As alluded to above, a comparison of response rates across infliximab treatment groups in ATTRACT suggests a dose response at the lower end of the dosing range. In clinical practice, infliximab treatment is usually begun at a dose of $3 \mathrm{mg} / \mathrm{kg}$ every eight weeks. However, the product labelling does allow for dosing flexibility within the $3 \mathrm{mg} / \mathrm{kg}-10 \mathrm{mg} / \mathrm{kg}$ every four to eight week range. Anecdotal observations indicate some patients receiving infliximab at a dose of $3 \mathrm{mg} / \mathrm{kg}$ every eight weeks experience a disease flare at the end of the eight week interval, prompting empirical boosts in the infliximab dose to improve treatment response. There have been no controlled studies testing if such an incremental dosing strategy is more effective than keeping the dose stable at $3 \mathrm{mg} / \mathrm{kg}$ every eight weeks.

A post hoc analysis of data from ATTRACT has provided evidence for a significant relation between the extent of clinical improvement and trough serum concentrations of infliximab. ${ }^{11}$ For some patients, optimal suppression of disease activity may require sustained inhibition of TNF $\alpha$ activity. About $25 \%$ of patients in the $3 \mathrm{mg} / \mathrm{kg}$ every eight week group had no detectable infliximab in their serum immediately before the next dose. This group tended to have a lower proportion of ACR20 responders compared with patients with detectable trough serum concentrations of infliximab. However, for the individual patient, a trough level would not probably be a reliable guide for making a dosage adjustment because of the imprecise relation between trough serum levels and the extent of clinical response. In contrast, pharmacokinetic modelling can provide valuable information for empiric dosing changes. Based on the ATTRACT data, models predict that shortening the interval between infusions from eight to six weeks produces higher trough serum concentrations of infliximab than increasing the dose by $100 \mathrm{mg}$ (for example, the amount in a vial of drug). ${ }^{11}$ For the patient with a suboptimal response, the preferred strategy may be to shorten the treatment interval rather than increasing the infliximab dose.

Additional studies are in progress to learn more about the role of infliximab treatment in this setting. Will patients with early disease benefit from starting infliximab treatment (or other TNF $\alpha$ inhibitor) with MTX soon after disease onset? Will treatment effectiveness wane over time because of the production of antibodies to infliximab? Can sustained infliximab treatment lead to healing of bone erosions? Future research promises to shed light on the most appropriate niche for infliximab treatment in this setting.

\section{Ankylosing spondylitis and psoriatic arthritis}

Like for RA, infliximab has been shown in several studies to potently reduce the signs and symptoms of ankylosing spondylitis. New treatments for ankylosing spondylitis are sorely needed because of the limited options at present. The potential clinical efficacy of infliximab therapy for ankylosing spondylitis was examined in an open label study of 21 patients with active spondyloarthropathy (ankylosing spondylitis, 10; psoriatic arthritis, 9; undifferentiated spondyloarthropathy, 2). The study showed that infliximab $5 \mathrm{mg} / \mathrm{kg}$ given at weeks 0,2 , and 6 could produced substantial improvements in several different measures of disease activity. ${ }^{12}$ Moreover, a maintenance regimen of $5 \mathrm{mg} / \mathrm{kg}$ every 14 weeks was able to maintain improvement in some cases, although many patients developed recurrent symptoms before their next treatment. ${ }^{13}$ These findings were confirmed in a 12 week, randomised, double blind, placebo controlled trial of infliximab involving 40 patients with active spondyloarthropathy. ${ }^{14}$ Eligible patients were randomly allocated in this trial to receive placebo or infliximab $5 \mathrm{mg} / \mathrm{kg}$ at week 0,2 , and 6 . The study population included 19 patients with ankylosing spondylitis, 18 patients with psoriatic arthritis, and 3 patients with an undifferentiated spondyloarthropathy. Improvements were noted in global 


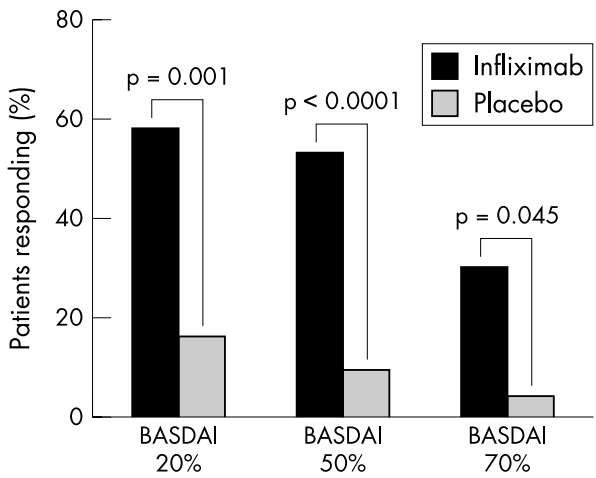

Figure 1 Clinical improvement of ankylosing spondylitis with infliximab treatment. Results from a randomised, double blind, placebo controlled trial. Eligible patients were treated with either infusions of placebo or infliximab $5 \mathrm{mg} / \mathrm{kg}$ at week 0,2 , and 6 . The primary outcomes were determined at week 12 . See text for description of the BASDAI outcome measure. Statistical differences in response rates between treatment groups were determined by Fisher's exact test. Data from Braun et al. ${ }^{16}$

assessments for pain, number of tender joints, axial assessments for pain and mobility, and functional disability.

After encouraging results from an open label study, ${ }^{15}$ Braun and coworkers ${ }^{16}$ performed a similar 12 week, randomised, double blind, placebo controlled trial of infliximab treatment for patients with ankylosing spondylitis. In this trial, 70 eligible patients were randomised to receive either placebo or infliximab $5 \mathrm{mg} / \mathrm{kg}$ at weeks 0,2 , and 6 . Disease activity was evaluated using validated measures recommended by the ankylosing spondylitis working group. ${ }^{17}$ An important measure of disease activity is the Bath ankylosing spondylitis disease activity index (BASDAI), a questionnaire evaluating disease activity related to fatigue, spinal pain, peripheral arthritis, enthesitis, and morning stiffness. Other measures included the Bath ankylosing spondylitis functional index (BASFI), and the Bath ankylosing spondylitis metrology index (BASMI), which assesses the mobility of the spine and hip. Predetermined criteria were set in this study to define $20 \%$, $50 \%$, and $70 \%$ levels of improvement. ${ }^{16}$ Infliximab treatment was associated with significant improvement in all disease measures compared with placebo (fig 1). Together, these two controlled studies show infliximab therapy provides substantial short-term clinical benefit for patients with ankylosing spondylitis. Studies are in progress to determine the long term efficacy of infliximab treatment for this indication.

The experience with infliximab treatment for psoriatic arthritis has been relatively limited in comparison with that for ankylosing spondylitis. In a small pilot study, treatment with infliximab was associated with improvement in both the joint and skin manifestations. ${ }^{18}$ Also, in a small, randomised, placebo controlled trial, infliximab $5 \mathrm{mg} / \mathrm{kg}$ and $10 \mathrm{mg} / \mathrm{kg}$ given at weeks 0,2 , and 6 each produced significant clearing of psoriatic skin lesions compared with placebo, with a median time to response of four weeks. ${ }^{19}$ As etanercept treatment is beneficial for psoriatic arthritis, ${ }^{20}$ infliximab will probably show similar favourable effects in the treatment of this condition.

\section{CONCLUSIONS}

The clinical success of infliximab treatment for RA and certain other rheumatic diseases validates $\mathrm{TNF} \alpha$ as a crucial mediator of inflammatory disease mechanisms. However, the answer is not so simple because more than one quarter of patients with RA do not respond adequately to TNF $\alpha$ block. The reasons behind this differential response are of interest. A possible explanation is the heterogeneity of RA created by a vast array of intermingling genetic and environmental factors. Future research will aim at dissecting these factors and their relative contribution to individual expression of disease and response to treatment.

\section{Author's affiliations}

E W St Clair, Department of Medicine, Division of Rheumatology, Duke University Medical Center, Durham, NC, USA

Correspondence to: Dr E W St Clair, Box 3874, Duke University Medical Center, Durham, NC 27710, USA; stcla003@mc.duke.edu

\section{REFERENCES}

1 Knight DM, Trinh H, Le J, Siegel S, Shealy D, McDonough M, et al. Construction and initial characterization of a mouse-human chimeric anti-TNF antibody. Mol Immunol 1993;30:1443-53.

2 Elliott MJ, Maini RN. Feldmann M, Long-Fox A, Charles P, Katsikis $P$, et al. Treatment of rheumatoid arthritis with chimeric monoclonal antibodies to tumor necrosis factor $\alpha$. Arthritis Rheum 1993;36:1681-90.

3 Elliott MJ, Maini RN, Feldmann M, Kalden JR, Antoni C, Smolen JS, et al. Randomised double-blind comparison of chimeric monoclonal antibody to tumour necrosis factor $\alpha$ (cA2) versus placebo in rheumatoid arthritis. Lancet 1994;344:1 105-10.

4 Elliott MJ, Maini RN, Feldmann M, Long-Fox A, Charles P, Bijl H, et al. Repeated therapy with monoclonal antibody to tumour necrosis factor $\alpha$ (cA2) in patients with rheumatoid arthritis. Lancet 1994;344:1125-7.

5 Maini RN, Breedveld FC, Kalden JR, Smolen JS, Davis D, Macfarlane JD, et al. Therapeutic efficacy of multiple intravenous infusions of anti-tumor necrosis factor $\alpha$ monoclonal antibody combined with low-dose weekly methotrexate in rheumatoid arthritis. Arthritis Rheum 1998;41:1552-63.

6 Kavanaugh A, StClair EW, McCune WJ, Braakman T, Lipsky P. Chimeric anti-tumor necrosis factor- $\alpha$ monoclonal antibody treatment of patients with rheumatoid arthritis receiving methotrexate therapy. J Rheumatol 2000;27:841-50.

7 Maini R, St.Clair EW, Breedveld F, Furst D, Kalden J, Weisman M, et al Infliximab (chimeric anti-tumour necrosis factor $\alpha$ monoclonal antibody) versus placebo in rheumatoid arthritis patients receiving concomitant methotrexate: a randomised phase III trial. Lancet 1999;354:1932-9.

8 Lipsky PE, van der Heijde DMFM, St.Clair EW, Furst DE, Breedveld FC, Kalden JR, et al. Infliximab and methotrexate in the treatment of rheumatoid arthritis. N Engl J Med 2000;343:1594-602.

9 Lipsky P, van der Heijde D, St.Clair EW, Smolen J, Furst D, Kalden J, et al. 102-wk clinical and radiologic results from the ATTRACT trial: A 2 year, randomized, controlled, phase 3 trial of infliximab (Remicade ${ }^{\mathrm{TM}}$ ) in patients with active rheumatoid arthritis despite methotrexate. Arthritis Rheum 2000:43 (suppl):S269.

10 Van der Heijde D. Plain X-rays in rheumatoid arthritis: overview of scoring methods, their reliability and applicability. Baillieres Clin Rheumatol 1996;10:435-3.

11 St.Clair EW, Wagner CL, Fasanmade AA, Wang B, Schaible T, Kavanaugh $A$, et al. The relationship of serum infliximab concentrations to clinical improvement in rheumatoid arthritis. Results from ATTRACT, a multicenter, randomized, double-blind, placebo-controlled trial. Arthritis Rheum 2002;46:1451-9.

12 Van den Bosch F, Kruithof E, Baeten D, de Keyser F, Mielants H, Veys EM. Effects of a loading dose regimen of three infusions of chimeric monoclonal antibody to tumour necrosis factor $\alpha$ (infliximab) in spondyloarthropathy: an open pilot study. Arthritis Rheum 2000;59:428-33

13 Kruithof E, Van den Bosch F, Baeten D, Herssens A, de Keyser F, Mielants $\mathrm{H}$, et al. Repeated infusions of infliximab, a chimeric anti-TNF $\alpha$ antibody, in patients with active spondyloarthropathy: one year follow-up. Ann Rheum Dis 2002;61:207-12.

14 Van den Bosch F, Kruithof E, Baeten D, Herssens A, de Keyser F, Mielants $\mathrm{H}$, et al. Randomized double-blind comparison of chimeric monoclonal antibody to tumor necrosis factor $\alpha$ (infliximab) versus placebo in active spondyloarthropathy. Arthritis Rheum 2002;46:755-65

15 Brandt J, Haibel H, Cornely D, Golder W, Gonzalez J, Reddig J, et al. Successful treatment of active ankylosing spondylitis with the anti-tumor necrosis factor $\alpha$ monoclonal antibody infliximab. Arthritis Rheum 2000;43:1346-52

16 Braun J, Brandt J, Listing J, Zink A, Alten R, Golder W, et al. Treatment of active ankylosing spondylitis with infliximab: a randomised controlled multicentre trial. Lancet 2002;359: 1 187-93.

17 Van der Heijde D, Bellamy N, Calin A, Dougados M, Khan MA, van der Linden S. Preliminary core sets for endpoints in ankylosing spondylitis. J Rheumatol 1997;24:2225-9.

18 Oglivie AL, Antoni C, Denchant C, Manger B, Kalden JR, Schuler G, et al. Treatment of psoriatic arthritis with anti-tumor necrosis factor- $\alpha$ antibody clears skin lesions of psoriasis resistant to treatment with methotrexate. Br J Dermatol 2001;144:587-9.

19 Chaudhari U, Romano P, Mulcahy LD, Dooley LT, Baker DG, Gottlieb $A B$. Efficacy and safety of infliximab monotherapy for plaque-type psoriasis: a randomised trial. Lancet 2001;357:1842-7.

20 Mease PJ, Goffe BS, Metz J, VanderStoep A, Finck B, Burge DJ. Etanercept in the treatment of psoriatic arthritis and psoriasis: a randomised trial. Lancet 2000;356:385-90 